\title{
Uncertainty and precaution in environmental management: Insights from the UPEM conference
}

\author{
Jeroen P. van der Sluijs* \\ Copernicus Institute for Sustainable Development and Innovation, Utrecht University, Heidelberglaan 2, 3584 CS Utrecht, The Netherlands
}

Received 20 September 2004; accepted 15 December 2005

Available online 22 March 2006

\begin{abstract}
Communication across the science-policy interface is complicated by uncertainty and ignorance associated with predictions on which to base policies. The international symposium "Uncertainty and Precaution in Environmental Management" (UPEM) addressed the philosophy, approaches and scientific tools associated with the analysis and communication of uncertainty and ignorance to decisions makers in relation to the Precautionary Principle. This paper presents a sample of highlights and insights of UPEM of relevance to the environmental modeling communities. Key insights include: (1) Systematic long-term monitoring and learning are essential. (2) More attention is needed for model structure uncertainty and equifinality. (3) Explicit value articulation in environmental assessment is essential. (4) Sophisticated uncertainty assessment and Quality Assurance methods-such as the Walker et al. conceptual uncertainty framework, NUSAP, and codes of uncertaintyexplicit modeling practice from RIVM and EPA - are now available and on their way of becoming main stream. (5) There is a wide range of precautionary interventions (a ban is not the only option). (6) Legal and Ethical dimensions of precaution-such as liability, burden of proof, inter- and intra generational equity-require more thought. (7) The problems that developing countries face in implementing the Precautionary Principle need more attention.
\end{abstract}

(C) 2006 Elsevier Ltd. All rights reserved.

Keywords: Uncertainty; Ignorance; Precautionary principle; Quality assurance; Model pedigree

\section{Introduction}

Communication across the engineering/science-policy/ management interface is difficult. Uncertainty and ignorance associated with assessments and predictions on which to base policies make the communication even more difficult. A 3-day international symposium "Uncertainty and Precaution in Environmental Management" (UPEM) was held in Copenhagen on 7-9 June 2004. The symposium addressed the philosophy, approaches and scientific tools associated with the analysis and communication of uncertainty and ignorance to decisions makers. In particular, the interpretation of the Precautionary Principle was discussed from a scientific, ethical and legal perspective, in view of the developments in recent years. The issues addressed included integrated assessment,

\footnotetext{
* Fax: +31 302537601.

E-mail address: j.p.vandersluijs@chem.uu.nl
}

water management and chemical risk assessment. The ambition of UPEM was to convene the best in the field of analyzing and communicating the role of uncertainty and ignorance in political and managerial decision support.

UPEM brought together about 75 practitioners from all over the world from a multitude of disciplines working on different aspects to analyze, and cope with, uncertainty-many develop to a major extent policy sciences based on uncertainty and precaution. These sciences do not merely employ different methods of probabilistic risk assessment. Because they recognize deeper uncertainties, they necessarily invoke precaution (Ravetz, 2005).

The conference was a tribute to Poul Harremoës (19342003), initiator of the UPEM conference, who died unexpectedly just a few days before the deadline for abstracts for the conference. Poul was lead author of the influential EEA report "Late Lessons from Early Warnings, the Precautionary Principle 1896-2000" (Harremoës et al., 2001). 
A central notion at the UPEM is that the knowledge base available for decision-making on environmental risks and health risks in the context of sustainable development is characterized by imperfect understanding of the complex systems involved. Decisions will need to be made before conclusive scientific evidence is available. In the interface between science and policy, experts analyze and review available information derived from research for the purpose of helping decision makers to evaluate possible actions, or think about a problem. In this process of scientific assessment of environmental problems, they face large (partly irreducible) uncertainties, knowledge gaps, and imperfect understanding. At the same time the decision stakes are high, values are in dispute, and potential error costs of wrong decisions can be huge. The assessments tend to be dominated by models, scenarios, and assumptions rather than by scientific facts. These models are characterized by many (hidden) value loadings in problem frames, indicators, and assumptions.

In the footsteps of Funtowicz and Ravetz (1993), a widely shared insight amongst the participants of the UPEM conference is that the science involved in such issue-driven environmental risk assessments is in several ways radically different from the science of curiosity-driven classic laboratory practice. Assessment of risks such as those associated with anthropogenic climate change, GMOs, or endocrine disruptors, involve uncertainties of many sorts, not all of which can be effectively controlled in practice. Funtowicz and Ravetz (1993) introduced the term post-normal science for such issue-driven risk research in a context of hard political pressure, values in dispute, high decision stakes and high epistemological and ethical systems uncertainties. The name 'Post-Normal Science' is a commentary on the classic analysis by the American philosopher T.S. Kuhn, who in his Structure of Scientific Revolutions (1962) described 'normal science' as uncritical puzzle solving within an unquestioned framework, or 'paradigm'. As he said, this is what all scientists do most of the time, and most scientists do all the time. Scientists are prepared for this rigorous effort by a dogmatic scientific training with textbooks where the answers to scientific questions can be found in the back. This is further reinforced by naive and simplistic accounts of how scientists discover truth. However successful this approach had been in traditional disciplinary research, it meets its limits when society is confronted with the need to resolve transdisciplinary policy issues regarding trans-national and trans-generational environmental risk on which yet no unquestioned frameworks exist.

Sustainability and precaution are central to post normal science. The precautionary principle implies a need for transdisciplinary approaches to science and policy. Science for policy in the face of uncertainty requires new trans-disciplinary contacts and integration (internal extension of the peer community) on the one hand, and new "knowledge partnerships" with policy makers, Non Governmental Organizations (NGOs), industry, media and the public (external extension of the peer community) on the other hand to meet the challenges of quality control in the assessment of complex risks.
Because of the many uncertainties, traditional science is not able to sufficiently legitimize the drastic steps that may be needed to deal with complex risks. The traditional dominance of "hard facts" over "soft values" has been inverted: hard policy decisions may have to be made, based on soft facts. The assessment of risks and the setting of policy should therefore encompass public agreement and participation. In addition, participation is desirable to enhance the quality of the scientific input in the process. For, when facing the uncertainties involved in complex risks, scientists sometimes are lay people as well (Funtowicz and Ravetz, 1993). Stakeholders' reasoning, observation and imagination is not bounded by scientific rationality; this "extended" perspective can be beneficial when tackling the ill-structured and complex policy problems. Consequently, the knowledge and perspectives of the stakeholders can bring in valuable new views on the problem and relevant information on that problem. The latter is known as "extended facts" or "local knowledge". Stakeholders can contribute to knowledge in a number of ways. These include contributing knowledge on local conditions which may help determine which data are strong and relevant or which response options are feasible; providing personal observations of the risk and its effects which may lead to new foci for empirical research addressing dimensions of the problem which were previously overlooked; and creative thinking of mechanisms and scenarios through which different sectors of society may be affected. Scientific and technical discourse can benefit from inclusion of nonspecialist knowledge, wisdom, and perspectives of stakeholders on the problem at hand. Making full use of this reservoir of extra knowledge requires the establishment of an extended peer community (Funtowicz and Ravetz, 1996) and the inclusion of stakeholder knowledge and perspectives not only in the phase where response options are debated, but also in the problem framing and risk assessment processes that precede it.

The workshop had 45 presentations and was organized around themes and all sessions and presentations were plenary with ample room for discussion. The session themes were:

- Philosophy and terminology of precaution

- Uncertainty: philosophy concepts, terminology, methods

- Model quality assurance

- Case studies

- River basin, groundwater, GMOs, nature conservation, environment and health

- Participatory approaches

- Regulation of chemicals and water protection

- Legal aspects of precaution

Discussing all sessions and all contributions is unfeasible in the scope of this short review. Therefore a sample of highlights of the UPEM sessions on: (1) philosophy and terminology of precaution; (2) uncertainty: philosophy, concepts, terminology, methods; (3) model quality assurance, and (4) legal aspects of precaution that are of relevance for the IEMSS community will be summarized below. 


\section{Philosophy and terminology of precaution}

The precautionary principle is primarily a strategy to cope with scientific uncertainties in the assessment and management of risks. Essentially it is an appeal to prudence addressed to policy makers who must take decisions about products or activities that could be seriously harmful to public health and the environment. For that reason, this emerging principle of international law does not offer a predetermined solution to every new problem raised by scientific uncertainty. On the contrary, it is just a guiding principle that provides helpful criteria for determining the most reasonable course of action in confronting situations of potential risk (Andorno, 2004).

In the literature and in international treaties and declarations, a variety of definitions can be found. The definitions vary from weak to strong. A widely cited definition stems from the Rio declaration (1992):

In order to protect the environment, the precautionary approach shall be widely applied by States according to their capabilities. Where there are threats of serious or irreversible damage, lack of full scientific certainty shall not be used as a reason for postponing cost-effective measures to prevent environmental degradation.

The triple negative notion in the Rio definition, that the absence of rigorous proof of harm does not justify inaction, is perceived to be weak. It forces the consideration of proactive intervention but does not require such intervention. The Wingspread definition on the other hand is strong and puts the burden of proof on the proponent of an action to show that it does not pose a danger of environmental harm:

When an activity raises threats of harm to human health or the environment, precautionary measures should be taken even if cause and effect relationships are not fully established scientifically ... [The] proponent of the activity, rather than the public, should bear the burden of proof.

Matthias Kaiser (2004) presented a useful list of conditions that need to be met to invoke the precautionary principle:

- There exist major uncertainties

- There exists some evidence and a science based scenario of possible harm

- The potential harm is significant, difficult to contain and possibly irreversible

- The potential harm relates to an important value, e.g. human health

- Uncertainties cannot now be significantly reduced without thereby increasing the chances for the harm to occur and/or without making the control of the harm more difficult.

The last condition in the list may need some elaboration. If we take genetically modified organisms (GMOs) as an example, we cannot fill up our knowledge gaps on the risks of GMOs without doing field experiments to get empirical evidence to test a number of hypotheses and assumptions made in the risks assessments. However, doing the field experiments increases the possibility that irreversible harm occurs.

Kaiser further stressed that it is frequently incorrectly assumed that application of the PP always implies a no-go, i.e. a ban or a moratorium. Instead, applying the PP means to find strategies that either significantly reduce the probability of the possible harm to occur, or contain the scope of the harm should it occur. In practice there is a variety of PP strategies at hand to choose from, ranging from a total ban (based on international agreement) or a moratorium (time-limited until knowledge or technology is significantly improved) to a "go-slow" strategy (limiting the numbers for a long period of time) or a strategy of "step-by-step and case-by-case evaluations" before further advances, to the establishment of an effective long term monitoring system.

In his presentation, David Gee emphasized that to better understand the concept of the precautionary principle and to avoid misunderstandings and confusions, it is useful to elaborate on what the PP is not and on what key features distinguish it from other guiding principles in policy making to protect human health and the environment.

The PP is not an element of a standard risk-assessment. It comes in addition to it, as a consistent supplement to risk analysis, or when no basis for a satisfactory risk analysis is given. Neither is PP an (in any case unrealistic) attempt to realize a zero-risk level for society. Instead, it aims to achieve lower/more acceptable risks/hazards with lower overall costs, both quantifiable and non-quantifiable.

The PP is also not a prediction-it is a process that may/ may not lead to exposure reduction measures. It is not the same as "prevention" which is concerned with known risks for which there exist a credible way to quantify probability. "Precaution" deals with uncertain, poorly known hazards and risks. For instance, restrictions on asbestos or smoking in 1950/1960s would have involved both Precaution and Prevention, but bans in 2003 are Prevention only because nowadays these risks are well known.

Further we need to be aware that (as with any other policy tool) the PP cannot be proof against misuse or bad decision making.

The PP is not a brake but a stimulant on innovation; it can also combat monopolies. Its application has stimulated development of innovative alternatives for CFCs, asbestos, and PCBs. It is intended to control, but not to hamper technological progress.

The PP focuses on trying to improve the management of scientific uncertainty and ignorance in situations of high stakes, where both regulatory action and inaction can have costly but unforeseeable impacts. It provides a framework for approaching and implementing decision-making where uncertain science and divergent interests require appropriate action. It is not based on anxiety/emotion-but is a rational decision rule, based in ethics, that aims to use the best of the "systems sciences" of complex processes to make, hopefully, wiser decisions (Gee and Krayer von Krauss, 2005).

Many references were made during the UPEM conference to the Harremoës et al. (2001) Late Lessons from Early 
Warnings report in which 12 lessons were inferred from a large number of historic case studies. These lessons are presented in Box 1.

David Tàbara (2005) explored the diverging interpretations of precaution for the case of GM crops in Spain. By means of qualitative participatory integrated assessment (PIA), ideal typical accounts and uses of the precautionary principle and of the precautionary approach were identified: On the one hand, a case by case precaution which promotes and defends a somewhat limited one-per-one, step-by-step, procedure in the assessment and regulation of the attendant risks, costs or benefits of GM crops, but excludes the consideration of larger ethical and political issues. And on the other, a systemic precaution interpretation, mainly defended by civic and environmental groups, which appear to be closer to the conceptual and political framework of sustainability and which usually demands broader changes in social structure and institutional practices.

Three scenarios on the plausible causes and consequences of commercial GM crops policy futures and the role of the precautionary principle and of precaution in them were also developed. Further research found that these scenarios could be linked to two broader worldviews about different plausible societies, models of agriculture, and of the role of ethics in the management of science and technology. On the one hand, the 'enhanced agrofood business as usual model', corresponds to a worldview which takes both GM and a case-by-case precaution to reinforce current trends in global and national agricultural production systems, without introducing fundamental changes in social structures or in the regulatory and assessment agencies. And on the other, the new socially and ecologically diverse agrofood model, envisions an agrofood system

1. Twelve late lessons from early warnings (Harremoës et al., 2001)

A. "Broaden the Framing and Assumptions"

- Manage "risk", "uncertainty" and "ignorance"

- Identify/reduce "blind spots" within disciplines

- Assess/account for all pros and cons

- Analyze/promote alternative options

- Take account of stakeholder values

B. "Broaden Assessment Information"

- Identify/reduce interdisciplinary obstacles to learning

- Identify/reduce institutional obstacles to learning

- Use "lay", local and specialist knowledge

- Identify/anticipate "real world" conditions

- Ensure regulatory and informational independence

- Promote long term monitoring/research that is not tightly focused on the development of new technological fixes, quantitative solutions, or single individual national-state strategies. It is one that departs from a systemic view of precaution to enforce new practices and deeper socioeconomic reforms both at local and at a global levels. And in particular, those that would counter-balance the power of economic corporations with relation to political institution and that would lead to a more participative and socially and biologically diverse 'world'.

Tàbara argued that such worldviews, which go beyond limited expert rationalities or technical assessments on commercial GM crops, are used by policy makers in Spain, (rather than or in conjunction with expert assessments), to make complex decisions in situations of large uncertainties and high stakes.

\section{Uncertainty: philosophy, concepts, terminology, methods}

This session dealt with philosophy of uncertainty and conceptualization. In my own presentation (Van der Sluijs, 2005) I analyzed the phenomenon of uncertainty in the science policy interface using the "monster" metaphor borrowed from the work of Dutch philosopher of technology Martijntje Smits (in press) on the cultural domestication of technologies. I use her monster-concept to explore the way in which the scientific community responds to the monstrous uncertainties that they face in the production of the knowledgebase of complex environmental problems. Building on work of Mary Douglas (1966) on purity and danger in traditional cultures, Smits has developed a theory in which she explains the co-existence of public discomfort and fascination with certain new technologies such as GMOs by using the metaphor of a monster. The idea is that we are accustomed to order the world in terms of binary categories such as humans versus animals, organisms versus machines. Douglas has shown that such categories differ from culture to culture. They are the result of a social learning process. For the most part they are shared collectively, therefore they could be called cultural categories. They shape a symbolical reconstruction of worldly phenomena. A special case of confusion appears when at the same moment a phenomenon fits into two categories that were considered to be mutually excluding. Smits calls this ambiguous phenomenon, this unnatural being, a monster.

When we apply Smits' monster concept to the production of a knowledgebase for policy making on complex environmental problems we can make a number of interesting observations. The categories that we thought to be mutually exclusive and that now tend to get increasingly mixed up to create monsters in the science-policy interface include: knowledge versus ignorance, objective versus subjective, facts versus values, prediction versus speculation, science versus policy.

Smits distinguishes four styles of "monster-treatment" with different degrees of tolerance towards the abnormal. These styles are: monster-exorcism, monster-adaptation, monster-embracement and finally monster-assimilation. In the 
following I will explore each of these strategies for coping with the monster of uncertainty.

Monster-Exorcists want to expel the monster. Uncertainty causes discomfort and does not fit within symbolical order where science is seen as the producer of authoritative objective knowledge. They call for more objective research that should aim at "reducing uncertainties". There is a strong believe in "objective science": the puzzle can be solved. This view can be found in for instance the first scientific assessment of climate change by the IPCC: "We are confident that the uncertainties can be reduced by further research." (Houghton et al., 1990). The borders between facts and values, knowledge and ignorance, science and policy are seen as real and inflexible and often the categories are also seen as norms (as in the notion that is a good thing to keep science and policy, facts and values, objective and subjective separated). Yet monster-theory predicts these attempts will prove to be vain in the long run: for each head of the uncertainty monster that science chops off, several new monster heads tend to pop up due to unforeseen complexities.

It is interesting to see that for that reason, the International Geosphere Biosphere Programme (IGBP, 1992), one of the largest international research programmes on global change, concluded during their third Scientific Advisory Council Meeting in January 1993, that it might not be feasible to reduce uncertainties (Williamson, 1994). Williamson also notes that the increasing complexity of global models inevitably decreases the precision of their products and "full predictability of the earth system is almost certainly unattainable." He makes a case for the replacement of the research objective to reduce uncertainties by a pragmatic research goal to "provide reliable estimates of probability within defined limits, so that risks can be assessed and appropriate actions taken, rather than single value 'predictions' with spurious exactitude."

Another strategy to cope with unwelcome uncertainty that may fit in the monster exorcism style and that needs mention here for the sake of completeness is the strategic hiding of uncertainty. One can think here of keeping the uncertainties in knowledge claims deliberately under the table because they do not fit a political agenda, to avoid that ones knowledge claims are disputed, or because one is afraid that prevalence of uncertainty will be judged as poor science by the outside world.

The Monster Adaptation style attempts to fit the uncertainty monster back in the categories, a process that can be characterized as purification. In terms of taming the uncertainty monster this can be seen as attempts to quantify uncertainties. Monster adapters feel uncomfortable with anything that does not fit in a spreadsheet. They need numbers, for otherwise they cannot do their calculations that they deem to be the basis of rational decision support. Where there is no objective ground for quantification, monster adapters tend to use subjective probability and Bayesian approaches to quantify uncertainties in terms of the degrees of belief that experts assign to their knowledge claims. By normalizing the post normal along these lines, the classic paradigms of Decision Support striving for optimization of expected utility as rational risk management strategy can be maintained. Monster adaptation by purification is further evident in the tendency to build system models based on "objective science" and then to externalize the subjective parts and uncertainties into ranges of scenario's-grouped into story-lines representing different value orientations - that are used to feed these "objective" models. The model is then seen as grounded in science and belongs to the domain of the scientists. Policymakers and stakeholders are welcome to contribute their insights, but in the scenario's that feed into the models, not in the science of the models itself.

The limitations of the purification, or monster adaptation approaches are obvious in the many critiques of the models. The IPCC Special Report on Emission Scenarios clearly shows that different models fed with the same scenarios produce very different results. This reflects the significance of model structure uncertainties.

Further, several authors have shown that current models are not so objective as they claim to be: they contain many valueladen assumptions and stem from value laden problem framings (see for overviews for instance Van der Sluijs, 1997, 2002).

The third response, Monster Embracement welcomes the uncertainty and can perhaps be associated with fascination about the unfathomable complexity of our living planet Gaia. It creates the possibility to be filled with wonder and respect, something that was taken away by the engineering worldview in which science is able to understand and control nature, reflected in notions seeing the biosphere as something that can be managed. The schools of thought of Holism and attempts to integrate science and spirituality in Inclusive Science (Ken Wilber) can also be considered as embracing uncertainty, because it emphasizes the limits of the positivist reductionist schools of thought for which they provide alternatives.

Another type of response to monstrous uncertainty that can be seen as monster embracement is denial of the reality of environmental risks by pointing to all those uncertainties. A variety of techniques is used to deliberately raise doubts about the realness of environmental risks, such as distortion and magnification of uncertainties (making mountains out of molehills), and even acts "at variance with good scientific practice" (as recently the Danish Committee on Scientific Dishonesty qualified some of the things Lomborg did in his book The skeptical environmentalist). The unpleasant way in which such games are played and the mixture of valid and ungrounded criticisms that it produces, is the price that has to be paid for the key-advantage for quality control of the identification of weak spots in the knowledge base by those who have a strong incentive and drive to find these weak spots.

The fourth strategy, Monster Assimilation refers to not only adapting the monster, but also changing the cultural categories by which it is judged. As Smits (2002, in press) argues, in contrast to the other styles monster-assimilation makes use of the insight that cultural categories are flexible and constructible. In other styles, the uncertainty monster is somehow judged in terms of existing cultural categories and these cultural categories are in turn considered more or less as facts. 
Rethinking the categories that got mixed up in the monsters is at the core of the monster assimilation strategy. Post-normal science and other forms of reflexive science are clear instances of attempts to assimilate the uncertainty monster and give it a central and explicit place in a deliberative management of environmental risks. Because scientific consensus about the truth of complex environmental risks is unlikely to be achieved given the post-normal situation (facts uncertain, values in dispute, high decision stakes), we will have to drop our demand for a single certain truth and strive instead for transparency of the various positions and learn to live with ambiguity and pluralism in risk assessment.

Each of the four styles can be observed in the historic learning process and current practice of coping with the uncertainty monster in the science policy interface on complex environmental problems. We might see this ongoing process of learning to cope with complex systems as a dialectic process where one strategy tends to dominate the field until it fails followed by a rise of one of the other strategies. As evident in UPEM, we now seem to find ourselves in a phase with a growing focus on monster assimilation.

Martin Krayer von Krauss presented an application of a new three-dimensional framework for assessment of uncertainties in models jointly proposed by Walker et al. (2003), further to be referred to as the W\&H framework. Many other presentations at UPEM also highlighted this innovative new framework or referred to it. The $\mathrm{W} \& \mathrm{H}$ uncertainty analysis framework was put forth with the aim of providing a conceptual basis for the systematic treatment of uncertainty in modelbased decision support activities such as policy analysis, integrated assessment and risk assessment. It provides a heuristic tool that can be applied in decision support exercises to classify and report the various dimensions of uncertainty. The intention is to stimulate better communication among analysts as well as between them and policymakers and stakeholders.

At the core of the conceptual framework is the notion that uncertainty in models is best thought of as a three dimensional concept distinguishing location, level and nature of uncertainty. Relevant locations where uncertainty can manifest itself include context, model structure, inputs, parameters, and model outcome (result). Level of uncertainty ranges from Determinism (perfect knowledge) via Statistical Uncertainty (known probability distributions), Scenario Uncertainty (range of the possible outcomes known, but no credible basis for the assignment of probability distributions), and Identified Ignorance (unknown bounds of the set of potential outcomes and unknown probabilities), to Total Ignorance (don't know that we do not know).

The framework articulates diverse scholarly understandings of "uncertainty", "ignorance" and "quality" in science for policy. Nevertheless, experience with the W\&H framework has revealed that many of the concepts put forth are relatively unfamiliar - and perhaps somewhat controversial - to experts practicing decision support. Thus, efforts are required to communicate the $\mathrm{W} \& \mathrm{H}$ framework to experts in such a way that their knowledge of uncertainty is elicited adequately, without them being overly intimidated or confused by the novelty of the concepts they are presented with (Krayer von Krauss and Janssen, 2005).

Keith Beven contributed to the session by highlighting the issue of model structure uncertainty. In his view, models are wrong and are known to be wrong. The aim of science as a single true description of reality is extremely difficult to achieve in applications to places that are all unique and where (nonlinear) predictions are subject to input errors, evaluation errors, and model structural errors. There may instead be many descriptions that are compatible with current understanding and available observations (models as multiple working hypotheses). The concept of the single description may remain a philosophical axiom or theoretical aim but is impossible to achieve in practice, so we must accept that there may be many feasible descriptions, or a concept of equifinality, as the basis for a new approach (Beven, 2002; Beven, 2005).

\section{Model quality assurance}

The session on model quality assurance dealt with key issues such as model evaluation (Beck, 2002), peer review and extended peer review (Funtowicz and Ravetz, 1996), the NUSAP (Numeral Unit Assessment Spread Pedigree) system for multidimensional uncertainty assessment, model quality assurance practice and approaches (Risbey et al., 2005; Refsgaard et al., 2005), model pedigree, and questions of fitness for function. The RIVM/MNP Guidance for Uncertainty Assessment and Communication (Van der Sluijs et al., 2003; Janssen et al., 2005) provides a code of conduct that includes all of these notions in providing a structured approach to the analysis, interpretation, documentation, and communication of uncertainties and limitations in the available knowledge and methods used in the entire process of a given environmental assessment study, running from problem framing towards reporting the results and conclusions of a study, along with the systematic assessment and communication of the implications of these uncertainties on the robustness and scope of resulting knowledge claims and policy conclusions.

Pasky Pascual (2004) addressed recent developments within the US Environmental Protection Agency (EPA) regarding model quality assurance. In pursuing its mission to protect human health and to safeguard the natural environment, the EPA often relies on environmental models. These models sometimes become part of the controversy over environmental initiatives. Parties impacted by EPA regulations have at times successfully challenged these regulations in court by questioning the validity of the models upon which they were based. A recent article in the Washington Post on the Data Quality Act (2000 legislation that ultimately provides outsiders with mechanisms to raise questions about governmental information) quoted an academic who accused industry of deliberately "manufacturing uncertainty."

EPA recently drafted guidance to provide recommendations on how environmental models should be developed, evaluated, and applied for decision-making. EPA's Information Quality Guidelines establish a process for parties impacted by the Agency's use of models to question the data, methods, and 
assumptions underlying these models. The EPA guidance is structured into the sections: model development, model evaluation, and model application.

For example, Model Evaluation is the process to generate information to determine if a model and its analytical results are of a quality sufficient to serve as the basis for a decision. Key questions here include: is the model representation of a system supported by the requisite quantity and quality of available data? Have the principles of sound science been addressed? Does the model reasonably approximate the real system? Does it perform the specified task? These questions give you information that may be seen as a Model Pedigree.

EPA has also developed a web-accessible knowledge base to document information about the Agency's most frequently used models. While the guidance recommends what information about a model should be documented, the knowledge base serves as the repository where this information should be documented.

Many references were made to the NUSAP system (Funtowicz and Ravetz, 1990) and several applications of NUSAP (Van der Sluijs et al., 2005a, 2005b; Craye et al., 2005) were presented. NUSAP is a notational and analytical system, which aims to provide an analysis and diagnosis of uncertainty in the knowledge base of complex (environmental) policy problems. It captures both quantitative and qualitative dimensions of uncertainty and enables one to communicate these in a standardized and self-explanatory way. The basic idea is to qualify quantities using the five qualifiers of the NUSAP acronym: Numeral, Unit, Spread, Assessment, and Pedigree. In early applications, NUSAP was used to complement quantitative analysis with expert judgment of reliability (Assessment) and systematic multi-criteria evaluation of the different phases of production of a given knowledge base (Pedigree). Pedigree criteria can be: proxy representation, empirical basis, methodological rigor, theoretical understanding, and degree of validation. In new case studies presented at UPEM the pedigree assessment has been further extended to also address societal dimensions with criteria addressing different types of value ladenness, quality of problem frames etc. NUSAP analysis structures the in depth review of strengths and weaknesses of knowledge bases, including embedded assumptions and problem frames. In doing so it helps to focus research efforts on most problematic parts of a knowledge base. It can be used interactively in deliberative processes to structure the critical appraisal of knowledge bases. It can act as a "Patient Information Leaflet" to deliver policy-relevant quantitative information together with essential warnings on its limitations and pitfalls.

An important issue that was raised by Anne Ingeborg Myhr is the problem of Stretched Peer Review on unwelcome results (Myhr and Traavik, 2003; Myhr, 2005). For the Precautionary Principle to be effective, it is essential that early warnings are recognized in good time and taken seriously. The GMO case has learned however that scientists that publish preliminary findings indicating the possibility of serious harm by GMOs are aggressively jumped upon by a powerful network of scientists from the pro-GMO lobby that heavily criticize and actively discredit the scientists that bring the message that potentially constitutes an early warning. This takes the form of attacks on the scientists' credibility via newspapers and other fora. This phenomenon stretches the peer review process of healthy critical debate beyond the scientific journals and scientific communities and into an area of an unhealthy war against the whistleblowers through personal attacks in the public- and policy arenas. This may cause that scientists refrain from publishing preliminary research findings that may constitute an early warning, which is a highly undesirable development seen from the viewpoint of the Precautionary Principle.

\section{Legal aspects of precaution}

The session on legal aspects of precaution discussed issues arising from inter alia the US Data Quality Act, the WTO Sanitary and Phyto-Sanitary Agreement, Paradigms of good administration, principles of Sound Science, Level of evidence required to invoke the precautionary principle, burden of proof, and liability.

Liz Fisher (2005) presented two Paradigms of Good Administration that can be distinguished in contemporary discourses surrounding the Precautionary Principle: the deliberative constructive paradigm and the rational instrumental paradigm. Table 1 highlights the key differences between the paradigms.

Jürg Bally (2005) in his presentation defined liability as an obligation of a person under the applicable law to provide compensation for damage resulting from an action for which that person is deemed to be responsible: The person who causes a damage shall compensate it!

Henk Zandvoort (2005) presented a number of interesting examples from international environmental liability law. In oil pollution and nuclear accidents, third party liability is unconditional, but limited and channeled. For the use of fossil energy that causes greenhouse gas emissions leading to global climate change, under the Kyoto international climate policies no liability regime exists for damages from $\mathrm{CO}_{2}$ emissions. In the field of GMOs there is the Cartagena protocol, which also has no liability regime for ecological harm. Regarding chemicals in the environment (REACH), liability might have played a role (but apparently did not) in the negotiations regarding costs of evaluation vs. reduced environmental risks. Zandvoort noted that the Precautionary Principle demands that liability is

Table 1

Two paradigms of good administration (Fisher, forthcoming)

\begin{tabular}{ll}
\hline Deliberative-constitutive & Rational-instrumental \\
\hline administration constituted to address & Administration delegated very \\
complex problems & limited task \\
Emphasis on both qualitative and & Decision primarily scientific and \\
quantitative processes & $\begin{array}{l}\text { based on rational methodological } \\
\text { processes }\end{array}$ \\
Deliberation as problem solving & $\begin{array}{l}\text { Public concern expressed through } \\
\text { legislation }\end{array}$ \\
\hline
\end{tabular}


better given shape in international policies. Standards for proving the absence of risk should be inversely related to standards for liability of actors. Reduced burden of proof for prospected actors should translate into stricter liability.

\section{Insights from UPEM and the way ahead}

During the three days of high level presentations and discussions, a large number of key insights emerged that were shared amongst the UPEM participants. Information gathering, systematic long-term monitoring, and learning, is seen as essential to any precautionary approach to environmental management. More attention is needed for model structure uncertainty and the notion of equifinality along with a need for explicit value articulation in environmental assessment.

Sophisticated uncertainty assessment and Quality Assurance methods are now available such as the RIVM Uncertainty Guidance, the EPA Model Quality Guidance, NUSAP, and the $\mathrm{W} \& \mathrm{H}$ three-dimensional conceptual uncertainty framework. These new methods are on its way of becoming mainstream. Post-normal science is a challenge that slowly but steadily has started to invade traditional approaches-science has to play an active role as participant in policy processes. Methodological challenges remain as to how to further integrate different approaches to deal with uncertainty, in particular the more technical approaches and the approaches from the policy perspective.

The discussions identified a dilemma of scientists in accounting for uncertainties - if they overdo they may lose credibility, but if they do not communicate uncertainties they may lose legitimacy as well. A change in public understanding of the limits of scientific advice is needed so that the public and decision makers do no longer expect that scientists can provide ultimate answers regarding many contemporary complex risks. Further, it was recognized that responsible science requires to develop a good practice to communicate uncertainty across the science policy interface to avoid that value driven decisions are legitimized by "soft" scientific facts.

Regarding the Precautionary Principle, it was recognized that there is a wide range of precautionary interventions (a ban is not the only option). Legal and Ethical dimensions of PP require more thought. The importance of better giving shape to liability in international law was underlined. The final plenary discussion further revealed that the issue of PP and developing countries was under-addressed.

A selection of about 30 UPEM papers has been published in a peer reviewed special issue of the journal Water Science and Technology (2005: vol 52, 6). It was decided that as a follow-up there will be a UPEM +3 conference in 2007. Further an initiative was taken to establish a UPEM Young Scientist Club (coordinated by Martin Krayer von Kraus, DTU mkk@er.dtu.dk) that now has sought collaboration with a similar initiative from the EU Joint Research Centre to establish a Worldwide Virtual Network of Young Practitioners Working on Science And Society Issues (http://alba.jrc.it/science-society;).

\section{Acknowledgments}

I thank all UPEM participants for (co)shaping the ideas brought together in this summary paper. In particular I thank Martin Krayer von Krauss and Claudia Pahl Wostl for sharing their thoughts with me on which UPEM highlights to include in this summary and what we may conclude from the UPEM conference. I thank Jerry Ravetz and Claudia Pahl Wostl for useful comments and stylistic improvements on earlier versions of this text. Most of all we owe thanks to Poul Harremoës. His death came as a tremendous loss. Without Poul's energy and capacity to bring people from different backgrounds and disciplines together around the notions of sustainability and precaution, the UPEM could never have been so fruitful and inspiring. Comfort may be found in the fact that in UPEM and its follow-ups Poul's spirit remains alive.

\section{References}

Andorno, R., 2004. The precautionary principle: a new legal standard for a technological age. Journal of International Biotechnology Law 1 (1), $11-19$.

Bally, J., 2005. Recent developments in the field of international liability regimes to tackle environmental risks. Water Science \& Technology 52 (6), 51-57.

Beck, M.B., 2002. Model evaluation and performance. In: Encyclopedia of Environmetrics, vol. 3. John Wiley \& Sons, New York. 1275-1279.

Beven, K., 2002. Towards a coherent philosophy for modelling the environment. Proceedings of the Royal Society of London, A 458 (2026), 2465-2484.

Beven, K., 2005. On the concept of model structural error. Water Science \& Technology 52 (6), 167-175.

Craye, M., Van der Sluijs, J., Funtowicz, S., 2005. A reflexive approach to dealing with uncertainties in environmental health risk science and policy. International Journal for Risk Assessment and Management 5 (2), $216-236$

Douglas, M., 1966. Purity and Danger: An Analysis of the Concepts of Pollution and Taboo. Routledge., London, New York.

Fisher, E., 2005. Precaution, law and principles of good administration. Water Science \& Technology 52 (6), 19-24.

Funtowicz, S.O., Ravetz, J.R., 1990. Uncertainty and Quality in Science for Policy. Kluwer, Dordrecht, p. 229.

Funtowicz, S.O., Ravetz, J.R., 1993. Science for the post-normal age. Futures 25 (7), 735-755.

Funtowicz, S.O., Ravetz, J.R., 1996. Risk management, post-normal science, and extended peer communities. In: Hood, C., Jones, D.K.C. (Eds.), Accident and Design, Contemporary Debates in Risk Management. UCL Press, pp. $172-182$.

Gee, D., Krayer von Krauss, M.P., 2005. Late lessons from early warnings: towards precaution and realism in research and policy. Water Science \& Technology 52 (6), 24-34.

Harremoës, P., Gee, D., MacGarvin, M., Stirling, A., Keys, J., Wynne, B., Guedes Vaz, S., 2001. Late Lessons from Early Warnings: The Precautionary Principle 1896-2000. OOPEC, Luxembourg.

Houghton, J.T., Jenkins, G.J., Ephraums, J.J. (Eds.), 1990. Climate Change, The IPCC Scientific Assessment. Cambridge University Press, 365 pp.

IGBP, 1992. Reducing Uncertainties, International Geosphere Biosphere Programme. Stockholm.

Janssen, P.H.M., Petersen, A.C., Van der Sluijs, J.P., Risbey, J.S., Ravetz, J.R., 2005. A guidance for assessing and communicating uncertainties. Water Science \& Technology 52 (6), 125-131.

Kaiser, M., 2004. Multistakeholder application of the precautionary principle: the importance of transparent values, oral presentation at the international symposium uncertainty and precaution in environmental management, Copenhagen Denmark, 7-9 June 2004. 
Krayer von Krauss, M.P., Janssen, P.H.M., 2005. Using the W\&H uncertainty analysis framework with non-initiated experts. Water Science \& Technology 52 (6), 145-152.

Myhr, A.I., 2005. Stretched peer-review on unexpected results (GMOs). Water Science \& Technology 52 (6), 99-106.

Myhr, A.I., Traavik, T., 2003. Genetically modified crops: precautionary science and conflicts of interest. Journal of Agricultural and Environmental Ethics 16, 227-247.

Pascual, P., 2004. Model credibility for regulatory decision-making, oral presentation at the international symposium uncertainty and precaution in environmental management, Copenhagen Denmark, 7-9 June 2004.

Ravetz, J., 2005. The post-normal sciences of precaution. Water Science \& Technology 52 (6), 11-17.

Refsgaard, J.C., Henriksen, H.J., Harrar, W.G., Scholten, H., Kassahun, A., 2005. Quality assurance in model based water management-review of existing practice and outline of new approaches. Environmental Modelling \& Software 20, 1201-1215.

Rio declaration on environment and development, 1992. In: Brown Weiss, Edith (Ed.), International Environmental Law: Basic Instruments and References, 1992-1999. Transnational Press, Ardsley, NY. 1999.

Risbey, J., Van der Sluijs, J., Kloprogge, P., Ravetz, J., Funtowicz, S., Corral Quintana, S., 2005. Application of a checklist for quality assistance in environmental modelling to an energy model. Environmental Modeling \& Assessment 10 (1), 63-79.

Smits, M., 2002. Monsterbezwering, De culturele domesticatie van nieuwe technologie. Boom, Amsterdam.

Smits, M. Taming monsters. The cultural domestication of new technology. Science as Culture, in press.

Tàbara, J.D., 2005. Precaution and participatory integrated assessment of GM crops in Spain. Water Science \& Technology 52 (6), 107-113.
Van der Sluijs, J.P., 1997. Anchoring amid uncertainty: on the management of uncertainties in risk assessment of anthropogenic climate change, Ph.D. Dissertation, University of Utrecht.

Van der Sluijs, J.P., 2002. A way out of the credibility crisis of models used in integrated environmental assessment. Futures 34, 133-146.

Van der Sluijs, J.P., 2005. Uncertainty as a monster in the science policy interface: four coping strategies. Water Science \& Technology 52 (6), 87-92.

Van der Sluijs, J.P., Risbey, J.S., Kloprogge, P., Ravetz, J.R., Funtowicz, S.O., Corral Quintana, S., Guimaraes Pereira, A., De Marchi, B., Petersen, A.C., Janssen, P.H.M., Hoppe, R., Huijs, S.W.F., 2003. RIVM/MNP Guidance for Uncertainty Assessment and Communication: Detailed Guidance, Copernicus Institute for Sustainable Development. Utrecht University, and RIVM-MNP, Utrecht, The Netherlands. <www.nusap.net/sections. php $\% 63 \mathrm{op}=$ viewarticle\&artid $=17>$.

Van der Sluijs, J.P., Craye, M., Funtowicz, S.O., Kloprogge, P., Ravetz, J., Risbey, J., 2005a. Combining quantitative and qualitative measures of uncertainty in model based foresight studies: the NUSAP system. Risk Analysis $25(2), 481-492$.

Van der Sluijs, J.P., Craye, M., Funtowicz, S.O., Kloprogge, P., Ravetz, J., Risbey, J., 2005b. Experiences with the NUSAP system for multidimensional uncertainty assessment in Model based Foresight Studies. Water science and technology 52 (6), 133-144.

Walker, W., Harremoës, P., Rotmans, J., Van der Sluijs, J., Van Asselt, M., Jansen, P., Krayer von Krauss, M.P., 2003. Defining uncertainty: a conceptual basis for uncertainty management in model-based decision support. Journal of Integrated Assessment 4 (1), 5-17.

Williamson, P., 1994. Integrating earth system science. Ambio 23 (1), 3.

Zandvoort, H., 2005. Globalisation, environmental costs, and progress, the role of consensus and liability. Water Science \& Technology 52 (6), 43-50. 